\title{
Methylprednisolone injection improved symptoms for 1 year in patients with the carpal tunnel syndrome
}

Dammers JW, Veering MM, Vermeulen M. Injection with methylprednisolone proximal to the carpal tunnel: randomised double blind trial. BMJ 1999 Oct 2;319:884-6.

QUESTION: What is the effectiveness of a methylprednisolone injection in patients with the carpal tunnel syndrome?

\section{Design}

Randomised (allocation concealed*), blinded (clinician, patient, and outcome assessor),* placebo controlled trial with 1 year follow up.

Setting

Outpatient neurology clinic in a district general hospital in the Netherlands.

\section{Patients}

Patients $>18$ years of age (mean age $52 \mathrm{y}, 83 \%$ women) who had signs and symptoms of the carpal tunnel syndrome for $\geq 3$ months confirmed by electrophysiological tests. Patients who had already been treated for the carpal tunnel syndrome were excluded. Follow up was $100 \%$.

\section{Intervention}

Patients were allocated to receive a single injection of methylprednisolone, $40 \mathrm{mg}$, and lignocaine, $10 \mathrm{mg}$ (intervention group, $\mathrm{n}=30$ ), or lignocaine, $10 \mathrm{mg}$, alone (control group, $\mathrm{n}=30$ ) proximal to the carpal tunnel. In patients with bilateral symptoms, the arm with the most severe symptoms was included in the study.

\section{Main outcome measures}

Symptom improvement was defined as having no symptoms or minor symptoms requiring no further treatment at 1 month. Patients were also evaluated at 3, 6, 9, and 12 months.

For correspondence: Dr J W Dammers,

Department of

Neurology, Medical

Centre Alkmaar, $P O$

Box 501, 1800 AM

Alkmaar, the

Netherlands.

\section{Main results}

More patients in the intervention group had symptom improvement than did those in the control group at 1,3 , 6,9 , and 12 months $(\mathrm{p}<0.01)$ (table).

Methylprednisolone injection $v$ control for symptom improvement in patients with the carpal tunnel syndromet

\begin{tabular}{rrrll} 
Follow up & Methylprednisolone & Control & RBI (95\% Cl) & NNT (Cl) \\
\hline $1 \mathrm{mo}$ & $77 \%$ & $20 \%$ & $283 \%(96$ to 723$)$ & 2 (2 to 3$)$ \\
\hline $3 \mathrm{mo}$ & $63 \%$ & $7 \%$ & $850 \%(185$ to 3400$)$ & 2 (2 to 3$)$ \\
\hline $6 \mathrm{mo}$ & $57 \%$ & $7 \%$ & $750 \%(152$ to 3050$)$ & $2(2$ to 4$)$ \\
\hline $9 \mathrm{mo}$ & $53 \%$ & $7 \%$ & $700 \%(136$ to 2880$)$ & $3(2$ to 4$)$ \\
\hline $12 \mathrm{mo}$ & $50 \%$ & $7 \%$ & $650 \%(119$ to 2700$)$ & $3(2$ to 5$)$ \\
\hline
\end{tabular}

$\dagger$ Abbreviations defined in glossary; RBI, NNT, and $\mathrm{Cl}$ calculated from data in article.

\section{Conclusion}

In patients with the carpal tunnel syndrome, an injection of methylprednisolone was effective in improving symptoms for up to 1 year.

*See glossary.

\section{COMMENTARY}

This rigorous study by Dammers and colleagues of the benefits of methylprednisolone in the non-surgical management of the carpal tunnel syndrome used a methodologically sound design to show that 1 injection of methylprednisolone may prevent the need for surgical decompression in $43 \%$ of patients at 1 year.

Injections into the carpal tunnel have traditionally been used as a temporary solution. Previous studies of corticosteroid injections in managing the carpal tunnel syndrome have used an uncontrolled series design. 1 study examined 497 patients who were treated with steroid injections; of these, $14 \%$ reported no further symptoms, $12 \%$ improved, and $26 \%$ eventually required surgery. ${ }^{1}$ Another study examined the benefit of injections in 50 hands among 41 patients with a mean follow up of 18 months. ${ }^{2}$ At the conclusion of this study, $22 \%$ of the 50 hands were free of symptoms. Patients with minimal or intermittent symptoms and negative physical examinations had the highest success rate, whereas patients with persistent numbness or thenar atrophy had the lowest success rate. Yet another study reported that injections gave complete relief of all symptoms in $30 \%$ to $40 \%$ of patients, with relief lasting from several weeks to 6 months; a further $10 \%$ to $20 \%$ of patients gained partial benefit from injection, although most of these patients eventually needed surgery. ${ }^{3}$ Dammers and colleagues do not report how many patients eventually went on to surgery, but we might assume that the patients who did not respond to steroid therapy became surgical candidates.

Methylprednisolone injection into the carpal tunnel is strictly a one time procedure. Repeated injections carry the risk for tendon rupture and nerve damage. The technique is easily learned but should be mastered through hands on training with an experienced operator.

Herman Weinreb, MD

New York University Medical Center New York, New York, USA

1 Phalen GS. The carpal tunnel syndrome. Seventeen years' experience in diagnosis and treatment of six hundred fifty-four hands.J Bone Joint Surg 1966;48:211-28.

2 Gerlberman RH, Aronson D, Weisman MH. Carpal tunnel syndrome. Results of a prospective trial of steroid injection and splinting. J Bone Joint Surg 1980;62:1181-7.

3 Dawson DD, Hallett M, Millender LH. Entrapment Neuropathies Boston: Little, Brown; 1983. 